\title{
Técnicas Geomorfométricas Para a Identificação de Padrões de Relevo: Aplicação nas Cartas Curitiba e Cerro Azul, Estado do Paraná
}

\author{
Geomorphometric Techniques for the Identification of Relief Patterns: \\ Application in Curitiba and Cerro Azul Maps, State of Paraná
}

\author{
Willian Bortolini', Claudinei Taborda da Silveira² ${ }^{2}$ Ricardo Michael Pinheiro Silveira ${ }^{3}$, Julio Manoel França da Silva ${ }^{4}$ \\ 1 Universidade Federal do Paraná, willianbortolini@gmail.com \\ 2 Universidade Federal do Paraná, claudinei.ufpr@yahoo.com.br \\ 2 Universidade Federal do Paraná, ricardomichaelps@gmail.com \\ Recebido (Received): 13/03/2018 \\ 2 Universidade Estadual do Centro-Oeste, juliosilva.geografo@gmail.com \\ Aceito (Accepted): 29/08/2018
}

\begin{abstract}
Resumo: A representação da morfologia do relevo é um dos aspectos que constituem a cartografia geomorfológica (juntamente com as representações dos processos, gênese e dos materiais constituintes do relevo). Fazendo uso desse recurso, o objetivo do trabalho é empregar técnicas geomorfométricas para a identificação de padrões de relevo na escala 1:100.000, no Primeiro Planalto Paranaense, numa porção que compreende as cartas Curitiba (MI 2842) e Cerro Azul (MI 2826). Para isto foi gerado o Modelo Digital de Elevação (MDE), do qual foram obtidos quatro atributos topográficos: declividade, Índice de Posição Topográfica (IPT), amplitude altimétrica e média da declividade. A declividade foi calculada utilizando uma janela móvel 3x3 células, e os demais atributos a partir de raios circulares, cuja dimensão foi obtida pela moda do comprimento das vertentes, variando conforme as características das subunidades morfoesculturais presentes na área. Os atributos foram discretizados segundo parâmetros determinísticos, por meio do auxílio da campanha de trabalhos de campo que identificou os padrões de relevo. A declividade e o IPT foram combinados por álgebra de mapas, identificando as planícies fluviais. A amplitude altimétrica e a média da declividade foram combinadas para a identificação das colinas suaves, morrotes, morros ondulados, morros fortemente ondulados e morros elevados. Estes padrões de relevo foram caracterizados morfometricamente, além de serem relacionados com os aspectos geológicos, possibilitando a discussão acerca da gênese. Quanto à técnica empregada, esta mostrou-se aplicável à identificação dos padrões de relevo, apresentando resultados concordantes com as observações de campo, além de avançar quanto a otimização e o processo de delimitação dos padrões de relevo quando comparado as técnicas tradicionais.
\end{abstract}

Palavras-Chave: Mapeamento Morfológico do Relevo; Análise Digital do Relevo; Modelo Digital de Elevação; Atributos Topográficos.

\begin{abstract}
The representation of the morphology of relief is one of the aspects that constitute the geomorphological cartography (together with representation of processes, genesis and the materials constitute the relief. By using such a resource, the objective of this work is to employ geomorphometric techniques in order to identify relief shape patterns in a scale of 1:100,000, in the First Paraná Plateau, in a region that comprises the Curitiba and Cerro Azul maps. In this sense, a Digital Elevation Model (DEM) was generated, which gave four topographic features: slope, Topographic Position Index (TPI), altimetric range, and slope average. Slope was calculated using a $3 x 3$ mobile window, and the other features were calculated from circular radii, whose dimension was obtained by means of the modal length of the slopes, varying according to the characteristics of the morphoscultural subunits present in the area. The features were discretized according to deterministic parameters with help from a field campaign that identified the relief patterns. Declivity and TPI were combined by means of map algebra, with identification of river plains. The altimetric range and the declivity average were combined for identify low hills, hillocks, undulated hills, greatly undulated hills, and steep hills. In addition to being associated with geological aspects, these relief patterns were morphometrically characterized, allowing for the discussion on genesis. As for the technique, it showed to be applicable for the identification of relief patterns, generating results which are in accordance with field observations, in addition to making advances regarding optimization and the process of limiting relief patterns as compared to traditional techniques.
\end{abstract}

Keywords: Morphological Mapping of Relief; Digital Terrain Modeling; Digital Elevation Model; Topographic Attributes. 


\section{Introdução}

A cartografia geomorfológica é um conjunto de técnicas empregadas para representar sistematicamente as formas, a gênese, os processos associados e os materiais constituintes do relevo (GRIFFITHS et al., 2011), sendo as formas de relevo as unidades cartográficas a serem distinguidas e mapeadas (VERSTAPPEN, 2011). Esta categoria cartográfica tem como desafio lidar com a complexidade da representação de seu objeto (o relevo), aliada ainda ao fato de que a superfície terrestre é composta por formas distintas e de diferentes tamanhos, que variam segundo a escala de análise (ROSS, 1992).

Visando contribuir com a representação do relevo, Ross (op cit) desenvolveu uma metodologia de classificação taxonômica que considera seis táxons, sendo derivada das contribuições de Penck (1953), mediante o antagonismo das forças endógenas e exógenas na formação do relevo, e de Mescerjakov (1968), Gerassimov e Mescherikov (1968), mediante os conceitos de morfotextura, morfoestrutura e morfoescultura.

Pautados nesta proposta, foram realizados os mapas geomorfológicos do Estado de São Paulo (ROSS; MOROZ, 1997) na escala 1:500.000, o mapeamento geomorfológico do estado do Paraná (SANTOS et al., 2006; OKA-FIORI et al., 2006), que representou os três primeiros táxons geomorfológicos na escala 1:250.000, caracterizando um marco fundamental na pesquisa geomorfológica paranaense, devido ao fato de ser o primeiro mapeamento sistemático do relevo no estado; e o mapeamento geomorfológico do estado do Rio Grande do Norte (DINIZ et al., 2017).

Trabalhos realizados por Ponçano et al. (1981), Ross e Moroz (1997), Carneiro e Souza (2003), Silva (2010), Augustin et al. (2011) e CPRM e IPT (2014) adequaram o uso do termo padrões de relevo à definição do $4^{\circ}$ táxon da classificação de Ross (1992). Esse táxon é caracterizado como os tipos de formas de relevo individualizadas dentro de cada Unidade de Padrão de Formas Semelhantes, sendo semelhantes entre si tanto na morfologia quanto na morfometria, ou seja, no formato e no tamanho, bem como na idade.

A operacionalização tradicionalmente empregada na identificação de feições do relevo se apoiava na interpretação de fotografias aéreas e cartas topográficas, mais recentemente foram incorporadas as imagens de sensores remotos orbitais. Assim, enquanto Ross e Moroz (1997) se basearam na fotointerpretação, Carneiro e Souza (2003), Augustin et al. (2011), Silveira et al. (2012), Silva e Santos (2012), CPRM/IPT (2014) e Silveira e Silveira (2016) associaram ao método técnicas de interpretação de atributos topográficos derivados de Modelos Digitais de Elevação (MDEs). Entretanto, essa abordagem mais qualitativa demonstra dificuldade na delimitação de unidades geomorfológicas, isto devido ao problema da subjetividade (SAMPAIO; AUGUSTIN, 2014).

Porém, com o desenvolvimento das tecnologias da informática e das geotecnologias a abordagem morfométrica da superfície terrestre tem ganhado destaque (PIKE et al., 2009). Essa ciência, denominada geomorfometria, é conceituada como ciência da modelagem digital do terreno (WILSON, 2012), caracterizada por englobar os dados provindos dos MDEs e as técnicas para análise topográfica e visualização. Ela possui como seu foco a extração de mensurações (parâmetros) e feições espaciais (objetos) dos MDEs (WILSON, 2012).

Segundo Dikau (1989), a identificação de feições do relevo pautado em aspectos quantitativos deve proporcionar uma classificação objetiva das feições do relevo formadas por componentes definíveis, apresentando conforme Evans e Minar (2008), o desafio de suprir a falta de precisão e objetividade dos métodos tradicionais. Deste modo, os MDEs são utilizados para o mapeamento e modelagem do relevo devido à sua riqueza de medidas e objetos que podem ser derivados pela análise dos dados de elevação (HENGL; MACMILLAN, 2009). Eles fornecem a possibilidade de cálculo de uma série de parâmetros derivados como a declividade, amplitude altimétrica, curvaturas, aspecto, entre outros (WILSON E GALLANT, 2000; ZHOU, 2008; HENGL E REUTER, 2009).

Os MDEs se referem a um arranjo regular bidimensional, em formato vetorial ou matricial, das elevações da superfície da Terra acima do nível médio do mar ou de algum outro referencial horizontal (WOOD, 1996; EL-SHEIMY et al., 2005). Estes modelos podem ter estrutura irregular na forma de redes de triângulo (triangulated irregular network - TIN) ou estrutura regular com representação matricial, sendo essa última a mais utilizada nas aplicações geomorfométricas (PIKE et al., 2009) por possibilitar os cálculos executados por meio de janelas móveis de geralmente $3 \times 3$ pixels.

A partir da aplicação de técnicas geomorfométricas como ferramenta de auxílio à classificação de formas de relevo, uma série de técnicas foram desenvolvidas, tendo destaque a classificação de feições de relevo desenvolvida por Wood (1996), o Índice de Posição Topográfica (IPT) proposto por Weiss (2001), a classificação hierárquica de formas de relevo adaptada para o ambiente informatizado de Dikau (1991), a 
classificação não-supervisionada de formas de relevo de Iwahashi e Pike (2007) e a segmentação de formas elementares por Minar e Evans (2008).

No Brasil, destacam-se algumas dessas aplicações: análise semiautomática de dados morfométricos por Steinke e Sano (2011) no Distrito Federal; aplicação de método de classificação não-supervisionada de formas de relevo por meio de árvore de decisões por Silveira et al. (2014) no Paraná, por Trentin et al. (2015) em uma bacia hidrográfica situada no oeste do Rio Grande do Sul e Gomes et al. (2018) no município de Campo Largo/PR; classificação geomorfométrica automatizada por Vasconcelos et al. (2012) aplicada no Parque Nacional Serra da Canastra/MG; emprego da classificação não-supervisionada de formas de relevo de Iwahashi e Pike (2007) por Guadagnin e Trentin (2014) na compartimentação geomorfológica de uma bacia hidrográfica no oeste do Rio Grande do Sul; emprego da classificação hierarquizada no mapeamento de formas de relevo por Tinós et al. (2014) no planalto de Poços de Caldas/MG, Silveira e Silveira (2015) em toda a abrangência do estado do Paraná e Silveira e Silveira (2016) na região central da Serra do Mar Paranaense; classificação das formas de relevo no estado do paraná por meio do Índice de Posição Topográfica (IPT) por Silveira e Silveira (2017) e emprego dos Silveira et al. (2017); classificação automatizada dos elementos de relevo com uso do conceito de geomorphons para a definição de compartimentos geomorfológicos no estado do Rio Grande do Sul por Robaina et al. (2016), em Tocantins por Robaina et al. (2017) e aplicação no Paraná por Silveira et al. (2018).

Objetivando identificar as formas de relevo adequadas ao $4^{\circ}$ táxon, CPRM e IPT (2014) fizeram uso dos atributos topográficos calculados a partir de MDE (no caso amplitude altimétrica e média da declividade), entretanto servindo apenas como ferramentas auxiliares à identificação dos padrões de relevo, sendo a fotointerpretação a ferramenta principal aplicada. Por sua vez, Bortolini et al. (2017) fez uso dos mesmos atributos topográficos, entretanto combinando e integrando estes por meio de álgebra de mapas, e consequentemente identificando de padrões de relevo na região sudoeste do Paraná.

No âmbito da representação da morfologia do relevo o trabalho visa empregar técnicas geomorfométricas semiautomatizadas, cujo método foi desenvolvido no projeto de Mapeamento Geomorfológico do Estado do Paraná apoiado em análise digital do relevo. Assim, o objetivo aqui proposto é de classificar os padrões de relevo, que se remete à representação morfológica equivalente ao $4^{\circ}$ nível taxonômico da proposta metodológica de Ross (1992), atendendo à escala 1:100.000, no recorte geográfico que abrange as cartas Curitiba (MI 2842) e Cerro Azul (MI 2826).

\subsection{Caracterização da área de estudo}

As cartas Curitiba (MI 2842) e Cerro Azul (MI 2826), escala 1:100.000, na área de abrangência do estado do Paraná totalizam $4.987 \mathrm{~km} 2$. Quanto aos aspectos geológicos, a área é constituída pelas unidades geológicas do Grupo Açungui, onde a Formação Capiru apresenta quartzitos nos cabeços de estratos e espigões, apresentando relevo de desenvolvimento preferencial segundo a direção NE-SW (ROSA FILHO; GUARDA, 2008); na mesma formação, existem metadolomitos, que hospedam feições cársticas (NASCIMENTO et al., 2012); há também a presença de corpos graníticos (MINEROPAR, 2001); e na porção sul abrange a Bacia Sedimentar de Curitiba (SALAMUNI; STELLFELD, 2001).

Além destas unidades, há no recorte estudado diques de rochas básicas, de evolução relacionada à fase de magmatismo fissural, com direção geral NW-SE, associados à estrutura chamada de Arco de Ponta Grossa (MINEROPAR, 2001). Ocorre ainda um sistema composto por falhas transcorrentes principais no sentido NE-SW e falhas e dobras secundárias, sendo seu principal exemplo a Falha da Lancinha (FIORI, 1992) (Figura 1).

Conforme a atlas geomorfológico do estado do Paraná, a área de estudo está contida na unidade morfoestrutural ( $1^{\circ}$ táxon) do "Cinturão Orogênico do Atlântico" e uma pequena parte na unidade "Bacias Sedimentares Cenozoicas e Depressões Tectônicas". Quanto à unidade morfoescultural ( $2^{\circ}$ táxon), a área está contida no "Primeiro Planalto Paranaense" e uma pequena parte nas "Planícies". Quanto ao $3^{\circ}$ táxon, são nove o número de subunidades morfoesculturais presentes na área (OKA-FIORI et al., 2006; SANTOS et al, 2006). Estas subunidades morfoesculturais se caracterizam por serem áreas que possuem o mesmo aspecto fisionômico quanto à dissecação do relevo (ROSS, 1992). A porção sul do recorte, próxima ao Rio Iguaçu, apresenta dissecação baixa ou média, já por sua vez, a porção norte, próxima ao Rio Ribeira, apresenta dissecação alta (OKA-FIORI et al., 2006).

Quanto aos aspectos hidrológicos, a área de estudo é drenada, majoritariamente, pela bacia do rio Iguaçu e pela bacia do rio Ribeira. Na porção extremo-noroeste do recorte, a área é drenada pela bacia do rio Itararé. 
Destas bacias, a primeira e a última drenam para o interior do continente, constituindo a bacia do rio Paraná. Por sua vez. A bacia do rio Ribeira drena em direção ao oceano Atlântico

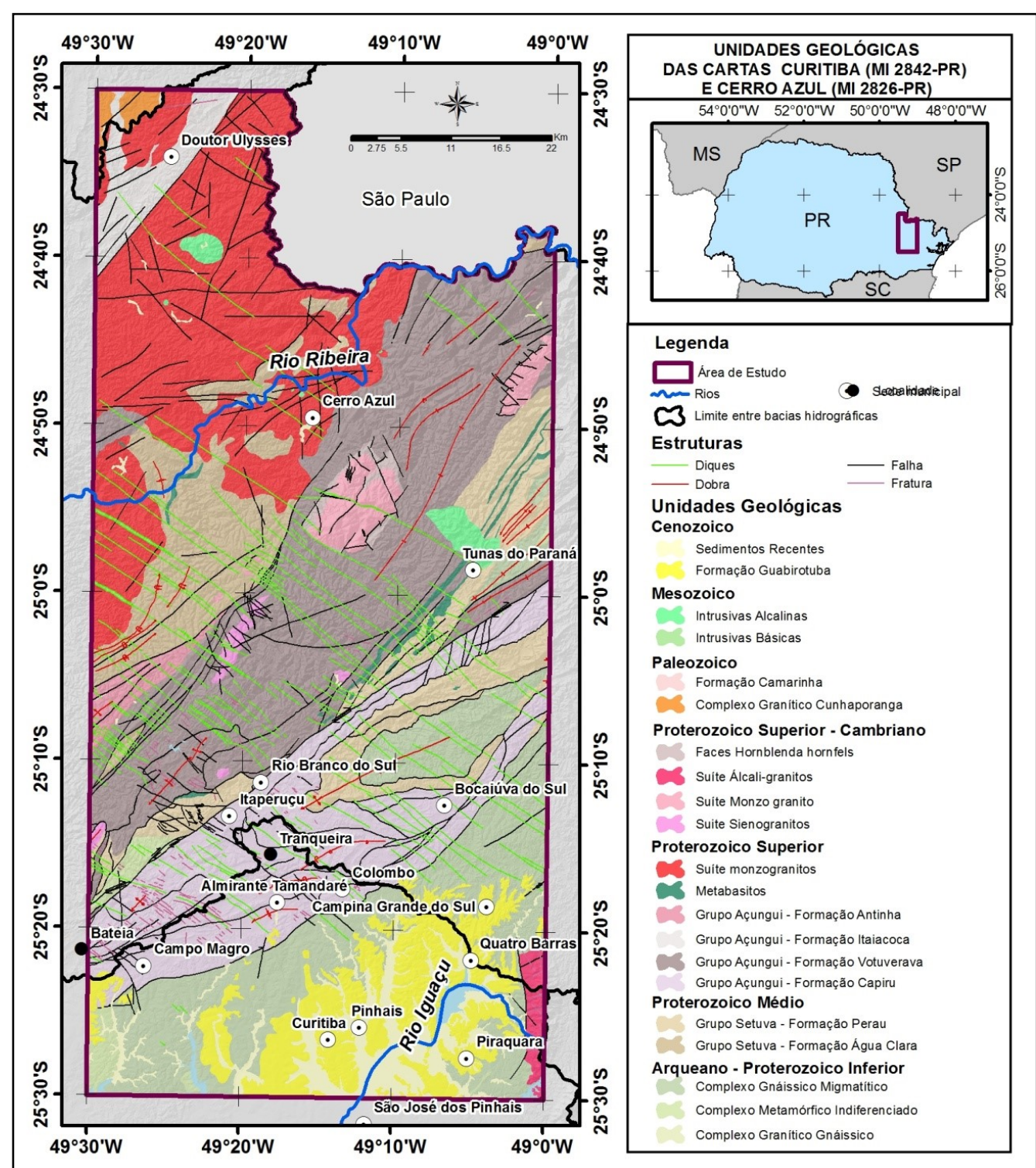

Figura 1: Mapa das unidades e das estruturas geológicas da área de estudo.

Fonte: Adaptado de Mineropar (2001).

\section{Materiais e Métodos}

O método empregado foi desenvolvido no âmbito do projeto de Mapeamento Geomorfológico do Estado do Paraná apoiado em análise digital do relevo, cuja execução foi composta por seis etapas (Figura 2):

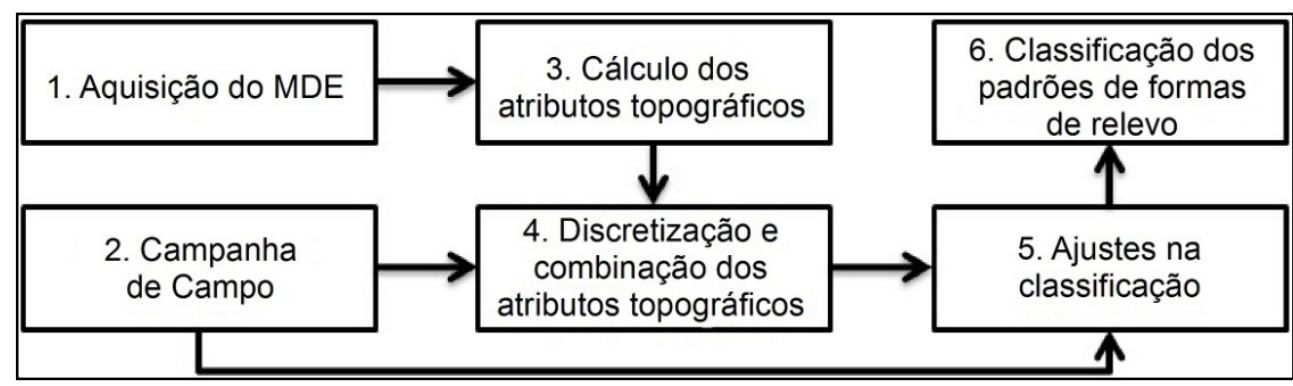

Figura 2: Fluxograma metodológico. 
Etapa 1: corresponde à aquisição do MDE da área de estudo. Como dados de entrada, foram levantadas as curvas de nível, pontos cotados e a hidrografia da base de dados topográfica do Departamento de Serviço Geográfico (DSG) e do Instituto Brasileiro de Geografia e Estatística (IBGE) ambas na escala 1:50.000.

O MDE foi gerado a partir do algoritmo determinístico ANUDEM, proposto por Hutchinson (1988), considerado hidrologicamente consistente. A definição da resolução espacial (ou tamanho do pixel) foi realizada a partir do método conhecido como complexidade do relevo (HENGL, 2006) (Equação 1), onde se calcula o tamanho máximo e o tamanho mínimo recomendado do pixel em função da relação entre as curvas de níveis e a área. O tamanho máximo é calculado levando em consideração toda a área em questão, e o tamanho mínimo é calculado levando em consideração os $5 \%$ de área com maior concentração de curvas de nível.

$$
p=\frac{A}{2 * \Sigma l}
$$

$p=$ tamanho do pixel;

$A=$ área;

$\sum l=$ soma do comprimento das curvas de nível;

O tamanho máximo para o pixel calculado para a área foi de $25 \mathrm{~m}$, enquanto o tamanho mínimo foi $13 \mathrm{~m}$. A resolução espacial utilizada foi definida pela média entre os dois valores anteriores (que é de $19 \mathrm{~m}$ ), devidamente arredondado para $20 \mathrm{~m}$.

Etapa 2: corresponde à campanha de campo, foi realizada com o intuito de conhecer e discutir previamente as características do relevo, identificando os padrões de relevo presentes. Foram visitados 20 pontos amostrais, sendo classificados e descritos a partir de suas características geomorfológicas correspondentes ao $4^{\circ}$ táxon. Estes pontos serviram, posteriormente, como pontos de controle para a discretização dos atributos topográficos e para a validação dos resultados finais. Etapa 3: corresponde ao cálculo dos atributos topográficos declividade, Índice de Posição Topográfico (IPT), amplitude altimétrica e média da declividade.

A declividade foi calculada a partir de uma janela móvel $3 \times 3$ pixels (Figura 3), conforme as variáveis direcionais do modelo teórico de Horn (1981) (Equação 2.1; 2.2; 2.3).

\begin{tabular}{|c|c|c|}
\hline$Z_{1}$ & $Z_{2}$ & $Z_{3}$ \\
\hline$Z_{4}$ & $Z_{5}$ & $Z_{6}$ \\
\hline$Z_{7}$ & $Z_{8}$ & $Z_{9}$ \\
\hline
\end{tabular}

Figura 3: Janela $3 \times 3$.

$$
\begin{gathered}
f x=\frac{\left[\left(Z_{3}+2 Z_{6}+Z_{9}\right)-\left(Z_{1}+2 Z_{4}+Z_{7}\right)\right]}{8 L} \\
f y=\frac{\left[\left(Z_{1}+2 Z_{2}+Z_{3}\right)-\left(Z_{7}+2 Z_{8}+Z_{9}\right)\right]}{8 L}
\end{gathered}
$$

sendo $f x$ o gradiente leste-oeste da janela $3 \times 3, f y$ o gradiente norte-sul e $L$ o tamanho do pixel.

$$
\text { Declividade }=\sqrt{f x^{2}+f y^{2}}
$$


A amplitude altimétrica se caracteriza como a diferença entre a altimetria máxima e mínima de determinada área (Equação 3), dado por um raio circular de tamanho determinado a partir da análise de uma série de perfis de vertentes (Figuras 4A e 4C), que demonstraram o valor de comprimento predominante (da moda) na área analisada (Figura 4B):

$$
\text { Amplitude altimétrica }=A_{\max }-A_{\min } \quad \text { (Equação 3) }
$$

sendo $A_{\max }$ a altitude máxima presente no área do raio e $A_{\min }$ a altitude mínima.

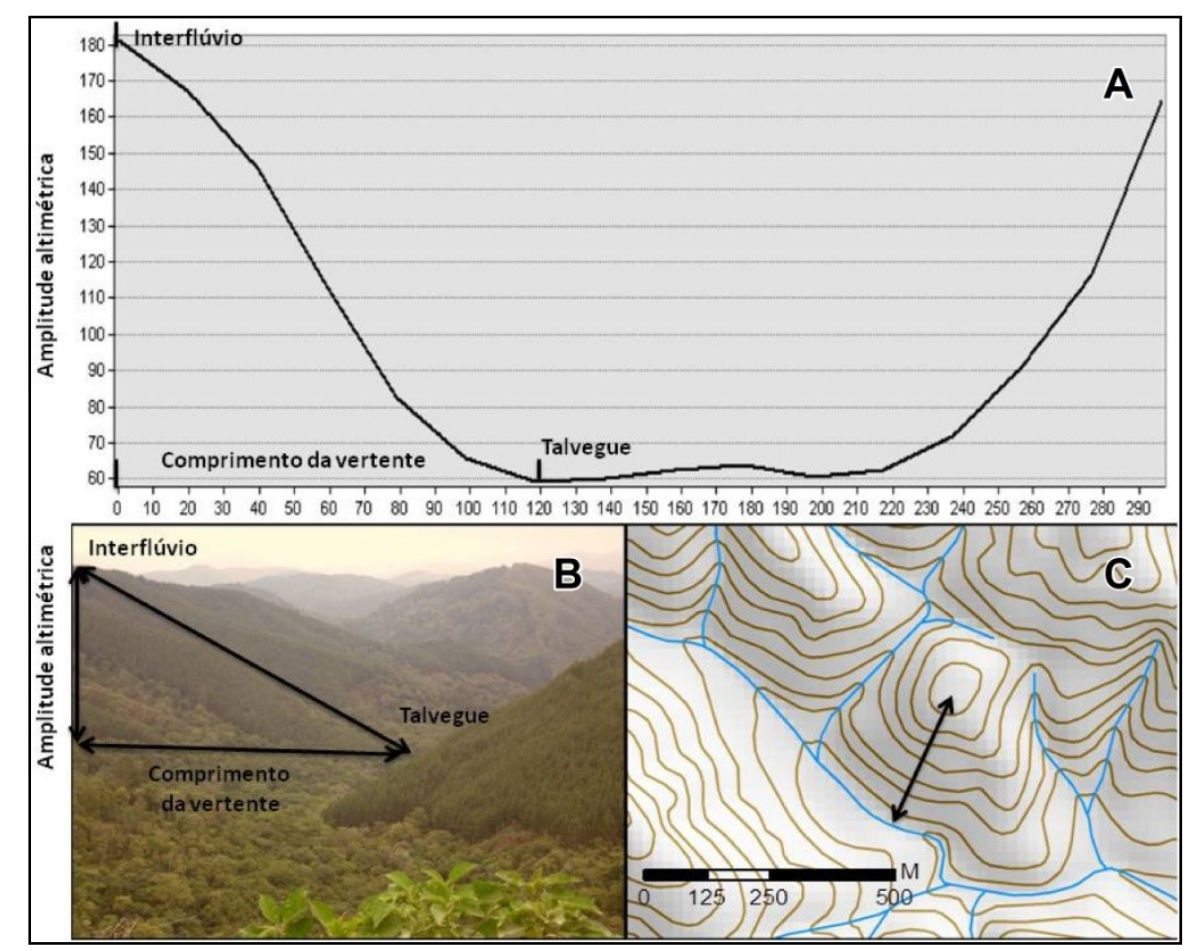

Figura 4: Perfil de vertente analisado para a determinação do tamanho do raio utilizado no cálculo dos atributos topográficos. É considerada como comprimento da vertente a distância do cateto adjacente, pois a projeção do mapa está em planta. (A) Representação do perfil de vertente, indicando os a posição e altitude do interflúvio e do comprimento da vertente, além da posição do talvegue. (B) Representação do perfil de vertente em campo. (C) Representação do perfil de vertente sobre a base altimétrica e hidrográfica.

A média da declividade é caracterizada como a média dos valores de declividade de uma determinada área (Equação 4), sendo esta área dada da mesma maneira como no cálculo da amplitude altimétrica.

$$
\text { Média da Declividade }=\frac{\sum D}{n}
$$

sendo $\sum D$ a soma das declividades de cada pixel abrangido pelo raio de análise e $n$ o número de pixels abrangidos pelo raio.

O IPT, proposto por Wilson e Gallant (2000) se caracteriza como a discrepância entre a elevação de um pixel central $\left(Z_{0}\right)$ e a média de elevação $(\bar{Z})$ (Equação 5). Para o cálculo da média de elevação foi utilizado um raio circular 10 vezes maior que o raio usado para modelagem dos dois últimos atributos topográficos.

$$
I P T=Z_{0}-\bar{Z}
$$


O procedimento de determinação do tamanho do raio para o cálculo dos atributos topográficos foi realizado para cada uma das nove subunidades morfoesculturais presentes no recorte, considerando que cada subunidade possui características morfométricas específicas, podendo ter comprimentos da moda de vertentes distintos. As dimensões dos raios de vizinhança determinados para cada subunidade morfoescultural são indicados no Tabela 1.

Tabela 1: Tamanho do raio por subunidade altimétrica.

\begin{tabular}{|c|c|c|c|}
\hline Subunidades morfoesculturais & $\begin{array}{c}\text { Raio de } \\
\text { análise de } \\
\text { vizinhança }\end{array}$ & Subunidades morfoesculturais & $\begin{array}{c}\text { Raio de } \\
\text { análise de } \\
\text { vizinhança }\end{array}$ \\
\hline 1.2.1 Blocos Soerguidos do Primeiro Planalto & $500 \mathrm{~m}$ & 1.2 .7 Planalto Dissecado de Rio Branco do Sul & $550 \mathrm{~m}$ \\
\hline 1.2.3 Planalto Dissecado de Adrianópolis & $550 \mathrm{~m}$ & 1.2 .8 Planalto Dissecado do Alto Ribeira & $400 \mathrm{~m}$ \\
\hline 1.2.4 Planalto de Curitiba & $350 \mathrm{~m}$ & 1.2 .9 Planalto do Jaguariaíva & $500 \mathrm{~m}$ \\
\hline 1.2.5 Planalto do Alto Iguaçu & $450 \mathrm{~m}$ & 3.5 .2 Planícies Fluviais & $700 \mathrm{~m}$ \\
\hline 1.2.6 Planalto Dissecado de Tunas do Paraná & $400 \mathrm{~m}$ & & \\
\hline
\end{tabular}

Etapa 4: corresponde à discretização e integração dos atributos topográficos. Primeiramente, para a definição dos intervalos a serem adotados em cada atributo, foi necessário identificar e definir os padrões de relevo a serem mapeados, por sua vez, identificados a partir de observações de campo e interpretação visual do relevo sombreado.

Para a identificação das colinas suaves, colinas onduladas, morrotes ondulados, morrotes fortemente ondulados, morros ondulados, morros fortemente ondulados e morros elevados, foram utilizados os atributos amplitude altimétrica e média da declividade, discretizados segundo os intervalos mostrados na Tabela 2.

Tabela 2: Parâmetros de discretização da amplitude altimétrica e da média da declividade.

\begin{tabular}{|c|c|c|c|c|c|c|c|c|c|c|}
\hline \multirow{2}{*}{$\begin{array}{c}\text { Classes de } \\
\text { intervalo }\end{array}$} & \multicolumn{2}{|c|}{1.2 .1} & \multicolumn{2}{|c|}{1.2 .3} & \multicolumn{2}{|c|}{1.2 .4} & \multicolumn{2}{|c|}{1.2 .5} & \multicolumn{2}{|c|}{1.2 .6} \\
\hline & $\overline{\mathrm{AA}(\mathrm{m})}$ & MD (\%) & $\overline{\mathrm{AA}(\mathrm{m})}$ & MD (\%) & $\overline{\mathbf{A A}(\mathbf{m})}$ & MD (\%) & $\overline{\mathbf{A A}(\mathrm{m})}$ & MD (\%) & $\overline{\mathrm{AA}(\mathrm{m})}$ & MD (\%) \\
\hline Classe 1 & $<60$ & $<8$ & $<60$ & $<8$ & $<45$ & $<8$ & $<50$ & $<8$ & $<50$ & $<8$ \\
\hline Classe 2 & 60 a 80 & 8 а 30 & 60 a 80 & 8 a 30 & 45 a 65 & 8 a 30 & 50 a 70 & 8 a 30 & 50 a 70 & 8 a 30 \\
\hline Classe 3 & 80 a 120 & $>30$ & 80 a 120 & $>30$ & 65 a 90 & $>30$ & 70 a 100 & $>30$ & 70 a 100 & $>30$ \\
\hline Classe 4 & 120 a 210 & & 120 a 200 & & 90 a 180 & & 100 a 200 & & 100 a 200 & \\
\hline Classe 5 & $>210$ & & $>200$ & & $>180$ & & $>200$ & & $>200$ & \\
\hline \multirow{2}{*}{$\begin{array}{c}\text { Classes de } \\
\text { intervalo }\end{array}$} & \multicolumn{2}{|c|}{1.2 .7} & \multicolumn{2}{|c|}{1.2 .8} & \multicolumn{2}{|c|}{1.2 .9} & \multicolumn{2}{|c|}{3.5 .2} & & \\
\hline & AA (m) & MD (\%) & AA (m) & MD (\%) & AA (m) & MD (\%) & $\mathbf{A A}(\mathrm{m})$ & MD (\%) & & \\
\hline Classe 1 & $<60$ & $<8$ & $<50$ & $<8$ & $<70$ & $<8$ & $<60$ & $<8$ & & \\
\hline Classe 2 & 60 a 80 & 8 a 30 & 50 a 70 & 8 a 30 & 70 a 90 & 8 a 30 & 60 a 80 & 8 a 30 & & \\
\hline Classe 3 & 80 a 120 & $>30$ & 70 a 100 & $>30$ & 90 a 120 & $>30$ & 80 a 120 & $>30$ & & \\
\hline Classe 4 & 120 a 200 & & 100 à 200 & & 120 a 210 & & 120 a 210 & & & \\
\hline Classe 5 & $>200$ & & $>200$ & & $>210$ & & $>210$ & & & \\
\hline \multirow[t]{2}{*}{ Legenda: } & \multicolumn{8}{|c|}{$\mathrm{AA}=$ Amplitude altimétrica } & & \\
\hline & $\begin{array}{l}1.2 .1=\mathrm{Blo} \\
1.2 .3=\mathrm{Pla} \\
1.2 .4=\mathrm{Pla} \\
1.2 .5=\mathrm{Pla} \\
1.2 .6=\mathrm{Pla}\end{array}$ & $\begin{array}{l}\text { os Soergui } \\
\text { alto Dissec } \\
\text { alto de Cur } \\
\text { alto do Alt } \\
\text { alto Dissec }\end{array}$ & $\begin{array}{l}\text { los do Prime } \\
\text { do de Adria } \\
\text { tiba } \\
\text { Iguaçu } \\
\text { do de Tuna }\end{array}$ & $\begin{array}{l}\text { ro Planalto } \\
\text { hópolis }\end{array}$ & & $\begin{array}{l}1.2 .7=\mathrm{Pl} \\
1.2 .8=\mathrm{Pl} \\
1.2 .9=\mathrm{Pl} \\
3.5 .2=\mathrm{Pl}\end{array}$ & $\begin{array}{l}\text { nalto Dissec } \\
\text { nalto Dissec } \\
\text { nalto do Alt } \\
\text { nícies Fluvi }\end{array}$ & $\begin{array}{l}\text { ado de Rio } \mathrm{I} \\
\text { ado do Alto } \\
\text { Jaguariaív } \\
\text { is }\end{array}$ & $\begin{array}{l}\text { Sranco do St } \\
\text { Ribeira }\end{array}$ & \\
\hline
\end{tabular}

A integração dos atributos topográficos se deu por meio de álgebra de mapas, seguindo a combinação mostrada na Figura 5.

Para a identificação das planícies fluviais, foram utilizados os atributos topográficos IPT e declividade. O IPT foi discretizado em duas classes (<-0,5 desvio padrão e >-0,5 desvio padrão). A declividade, por sua vez, foi discretizada também em duas classes, com os intervalos variando conforme a subunidade morfoescultural. A necessidade de uso de intervalos distintos de declividade foi observada quando os resultados preliminares da classificação foram comparados ao mapeamento preexistente na área, realizado por Salamuni et al. (2013), que identificou as áreas de planícies fluviais no município de Curitiba. Para as subunidades Planalto de Curitiba e Planalto do Alto Iguaçu ela foi discretizada em $<5 \%$ e $>5 \%$; para a subunidade Planalto Dissecado de Tunas do Paraná foi discretizada em $<6 \%$ e $>6 \%$; e para as Planícies 
Fluviais foi discretizada em $<3 \%$ e $>3 \%$. O processo foi aplicado apenas para essas quatro subunidades morfoesculturais pois foram as únicas onde foram identificadas planícies fluviais.

\begin{tabular}{|c|c|c|c|c|c|c|c|c|c|}
\hline \multicolumn{2}{|c|}{ 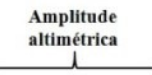 } & \multicolumn{2}{|c|}{ 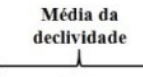 } & \multirow{2}{*}{ 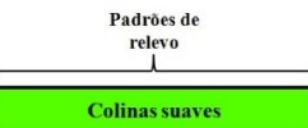 } & \multicolumn{2}{|c|}{ 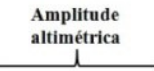 } & \multicolumn{2}{|c|}{ 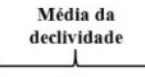 } & \multirow{2}{*}{$\underbrace{\substack{\text { Padrōes de } \\
\text { relevo }}}_{\text {Morros ondulados }}$} \\
\hline & & & Classe 1 & & & & & Classe 1 & \\
\hline \multirow[t]{3}{*}{ AA } & Classe 1 & MD & Classe 2 & Colinas onduladas & $\mathbf{A A}$ & Classe 4 & MD & Classe 2 & Morros ondulados \\
\hline & & & Classe 3 & Colinas onduladas & & & & Classe 3 & Morros fortemente ondulados \\
\hline & & & Classe 1 & Colinas suaves & & & & Classe 1 & Morros elevados \\
\hline \multirow[t]{3}{*}{$\mathbf{A A}$} & Classe 2 & MD & Classe 2 & Colinas onduladas & AA & Classe 5 & MD & Classe 2 & Morros elevados \\
\hline & & & Classe 3 & Morrotes ondulados & & & & Classe 3 & Morros elevados \\
\hline & & & Classe 1 & Colinas suaves & & & & & \\
\hline AA & Classe 3 & MD & Classe 2 & Morrotes ondulados & & & & & \\
\hline & & & Classe 3 & Morrotes fortemente ondulados & & & & & \\
\hline
\end{tabular}

Figura 5: Combinação de álgebra de mapas para o mapeamento dos padrões de relevo.

As áreas de IPT abaixo de -0,5 desvio padrão e com baixa declividade (abaixo de 3, 5 ou 6\%, dependendo da subunidade morfoescultural, como citado acima) foram combinadas por álgebra de mapas, delimitando as planícies fluviais.

Após a integração e combinação dos atributos topográficos, foi aplicado um filtro que removeu agrupamentos de até 2500 pixels $\left(\right.$ ou $\left.1 \mathrm{~km}^{2}\right)$. A aplicação do filtro está vinculada à hierarquia taxonômica pretendida pela classificação, sendo valor do filtro definido com base na hierarquia taxonômica de unidades de relevo de Dikau (1989). Para as áreas de planícies fluviais o valor definido foi metade do valor para os demais padrões, ou seja, 625 pixels (ou $0,25 \mathrm{~km}^{2}$ ).

Etapa 5: corresponde à realização de ajustes na classificação obtida, visando a incorporação de pequenas porções de padrão de formas de relevo ao padrão do seu entorno, por possuírem características semelhantes; o ajuste de áreas de contato entre padrões de relevo, que apresentaram limites que cortam as vertentes; e ajuste de áreas classificadas como determinado padrão de relevo que abrange apenas uma face de vertente. Esses ajustes foram realizados a partir de interpretação visual do relevo sombreado, como exemplificado na Figura 6.

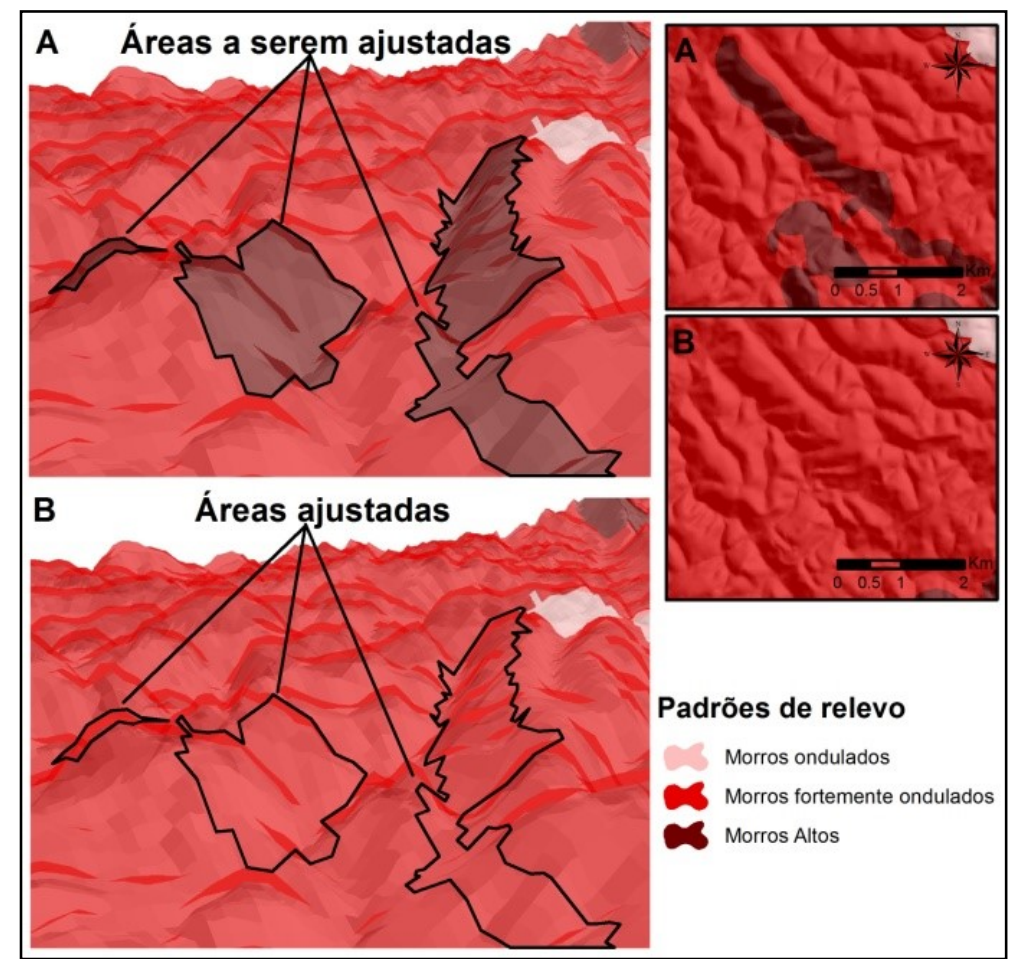

Figura 6: A: Exemplo de áreas a serem ajustadas manualmente. B: áreas após serem ajustadas manualmente. 
Etapa 6: corresponde à construção do mapa de padrões de relevo na escala 1:100.000 e a construção da legenda, onde cada padrão de relevo foi representado por polígonos, diferenciados por cores e por intensidade.

\section{Resultados e Discussões}

Foram identificados e classificados sete tipos de padrões de relevo na área de estudo, que possibilitaram maior detalhamento na representação da morfologia presente nas subunidades morfoesculturais mapeadas por Santos et al. (2006), proporcionando o aumento de escala e táxon geomorfológico (Figura 7).

a) Planícies fluviais (Figura 8A): são caracterizadas como as áreas planas do terço inferior das vertentes possuindo médias das declividades abaixo de 3\% na subunidade morfoescultural Planícies Fluviais, 5\% no Planalto do Alto do Iguaçu e no Planalto de Curitiba e 6\% no Planalto Dissecado de Tunas do Paraná. Esta variação de valores de declividade foi observada quando os resultados foram comparados ao mapeamento preexistente realizado por Salamuni et al. (2013).

Ocupando área de 162,21 km2 (3,25\% da área de estudo), tais planícies ocorrem apenas na bacia do rio Iguaçu, não sendo encontradas na bacia do rio Ribeira. Sua ocorrência apresenta correspondência com a área de deposição de sedimentos recentes apresentados nos mapeamentos geológico de Mineropar (2001) e Salamuni e Stellfeld (2001), e no mapeamento geomorfológico de Salamuni et al. (2013).

b) Colinas suaves (Figura 8B): são caracterizadas pela amplitude altimétrica abaixo de $65 \mathrm{~m}$ no Planalto de Curitiba; $70 \mathrm{~m}$ no Planalto do Alto Iguaçu, Planalto Dissecado de Tunas do Paraná e Planalto Dissecado do Alto Ribeira; $80 \mathrm{~m}$ nos Blocos Soerguidos do Primeiro Planalto, Planalto Dissecado de Adrianópolis, Planalto Dissecado de Rio Branco do Sul e Planícies Fluviais; e $90 \mathrm{~m}$ do Planalto do Alto Jaguariaíva. Quanto a média da declividade, apresentam-se sempre abaixo de $8 \%$. Suas vertentes variam de $500 \mathrm{~m}$ de comprimento até mais de $1000 \mathrm{~m}$, sendo mais extensas quando mais próximas às planícies fluviais. Seus vales abertos e os topos são suaves.

Este padrão de relevo ocupa área de 310,43 km2 (6,22\% da área de estudo), localizado majoritariamente próximo às planícies fluviais das principais drenagens da bacia do Alto Iguaçu.

c) Colinas onduladas (Figura 8C): ocupa área de $661,41 \mathrm{~km} 2(13,26 \%$ da área de estudo), estando localizadas principalmente na porção sul do recorte, além de pontos no norte e pontos centrais isolados, dominantemente em padrões em forma de colinas suaves ou morrotes ondulados.

São caracterizadas por amplitude altimétrica semelhante as encontradas nas colinas suaves, diferenciando-se destas em função dos valores médios de declividade que possuem (entre $8 \%$ e $30 \%$ ). Predominantemente, são constituídas por vertentes com comprimento entre 200 a $500 \mathrm{~m}$ de comprimento, vales fluviais abertos e topos ondulados.

d) Morrotes ondulados (Figura 8D): este padrão de relevo ocupa área de 688,85 km2 (13,81\% da área de estudo), estando próximos do padrão de formas em colinas onduladas, morros ondulados e morros fortemente ondulados. São caracterizados por amplitude altimétrica compreendida entre 45 a $65 \mathrm{~m}$ no Planalto de Curitiba; 50 a $70 \mathrm{~m}$ no Planalto do Alto Iguaçu, Planalto Dissecado de Tunas do Paraná e Planalto Dissecado do Alto Ribeira; 60 à $80 \mathrm{~m}$ nos Blocos Soerguidos do Primeiro Planalto, Planalto Dissecado de Adrianópolis Planalto Dissecado de Rio Branco do Sul e Planícies Fluviais; e 70 a 90 no Planalto de Jaguariaíva; e média da declividade acima de 30\%. E também pela amplitude altimétrica entre 65 à $90 \mathrm{~m}$ no Planalto de Curitiba; 70 a $100 \mathrm{~m}$ no Planalto do Alto Iguaçu, Planalto Dissecado de Tunas do Paraná e Planalto Dissecado do Alto Ribeira; 80 a $120 \mathrm{~m}$ nos Blocos Soerguidos do Primeiro Planalto, Planalto Dissecado de Adrianópolis Planalto Dissecado de Rio Branco do Sul e Planícies Fluviais; e 90 a 120 no Planalto de Jaguariaíva; e média da declividade entre 8 e 30\%.

A forma dos morrotes ondulados se apresenta como uma transição entre colinas onduladas e morros ondulados, possuindo no terço inferior e médio características semelhantes às colinas onduladas e no terço superior um pequeno topo aguçado ou arredondado.

e) Morros ondulados (Figura 8E): ocupam área de 580,51 km2 (11,64\% da área de estudo), localizados principalmente na bacia do rio Ribeira (porção centro-norte e centro-sul do recorte), próximo aos padrões de morros fortemente ondulados e morros elevados. São caracterizados pela amplitude altimétrica entre 90 e 180 m no Planalto de Curitiba; 100 e 200 m no Planalto do Alto Iguaçu, Planalto Dissecado de Tunas do Paraná e Planalto Dissecado do Alto Ribeira; 120 e 200 no Planalto Dissecado de Adrianópolis, Planalto Dissecado de Rio Branco do Sul; e 120 e 210 nos Blocos Soerguidos do Primeiro Planalto, Planalto 
Jaguariaíva e Planícies Fluviais; e média da declividade abaixo de 30\%. Apresentam vertentes de $250 \mathrm{~m}$ de comprimento até $500 \mathrm{~m}$ de comprimento, os vales são abertos e topos variando entre alongados/aguçados ou arredondados.

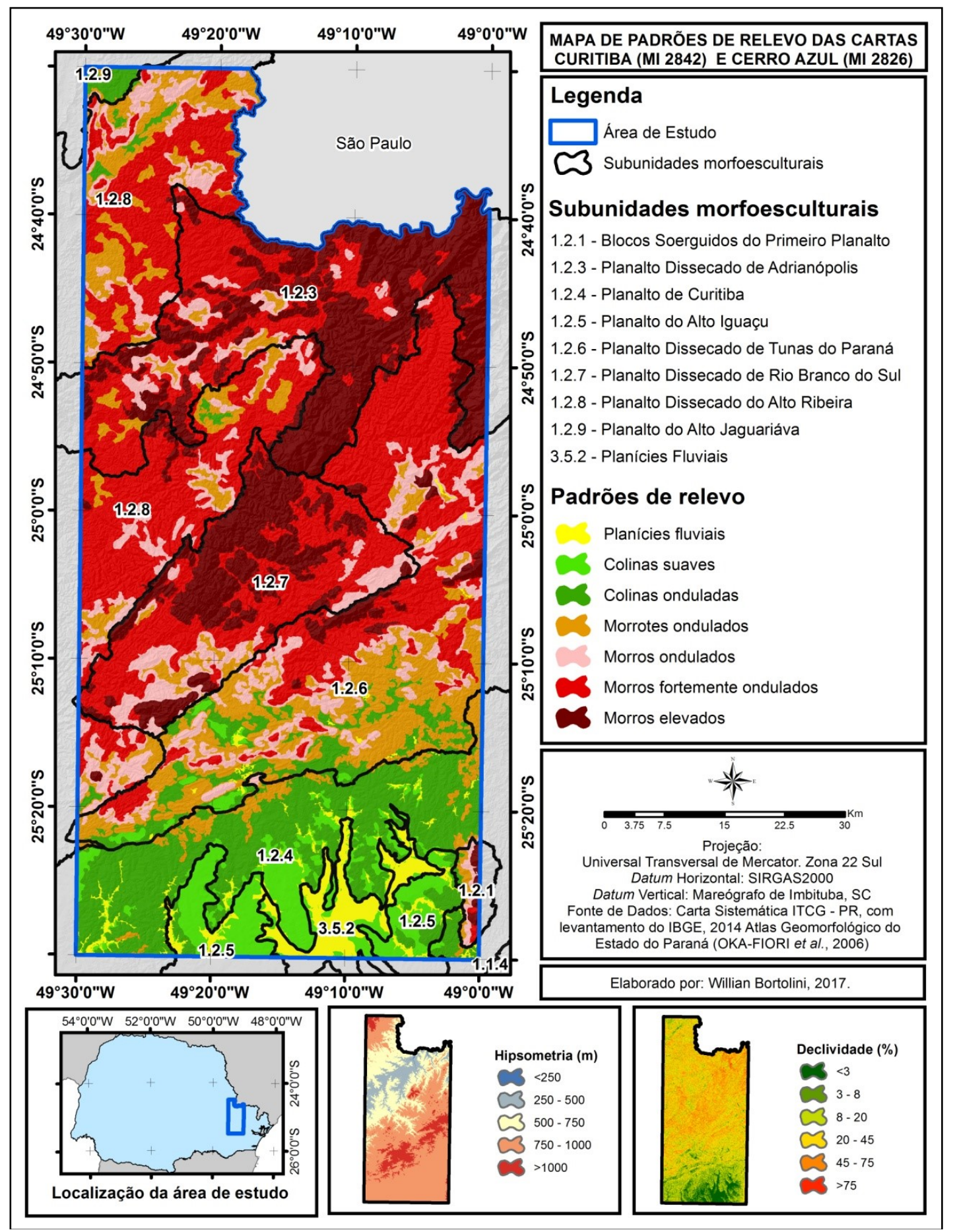

Figura 7: Mapa de padrões de relevo das cartas Curitiba e Cerro Azul. Fonte: Autores.

f) Morros fortemente ondulados (Figura 8F): com área de 1649,89 km2 (33,08\% do total), estão localizados principalmente na bacia do rio Ribeira (porção central e centro-norte do recorte), além de outros pontos isolados. São caracterizados pela amplitude altimétrica semelhante aos morros ondulados e média da declividade acima de $30 \%$. Apresentam vertentes de 200 a até $600 \mathrm{~m}$ de comprimento. Apresentam vertentes de 250 a até $700 \mathrm{~m}$ de comprimento. Os vales são entalhados e os topos são aguçados e arredondados na maior porção, e aguçados e com cristas alongados na zona central do recorte (sendo estes topos orientados na direção NW-SE).

g) Morros elevados (Figura 8G): possuem área de 933,91 km2 (18,73\% do total), localizados predominantemente na bacia do rio Ribeira (porção central e centro-norte). São caracterizados por amplitude 
altimétrica acima de $180 \mathrm{~m}$ no Planalto de Curitiba; $200 \mathrm{~m}$ no Planalto Dissecado de Adrianópolis, Planalto do Alto Iguaçu, Planalto Dissecado de Tunas do Paraná, Planalto Dissecado de Rio Branco do Sul e Planalto Dissecado do Alto Ribeira; ou $210 \mathrm{~m}$ nos Blocos Soerguidos do Primeiro Planalto, no Planalto de Jaguariaíva e Planícies fluviais. Apresentam vertentes de 200 a até $900 \mathrm{~m}$ de comprimento. Os vales são entalhados e os topos são aguçados e arredondados na maior porção, e aguçados e com cristas alongados na zona central do recorte, sendo estes topos orientados na direção NW-SE. Há também a presença de topos com estas mesmas características na porção nordeste, entretanto com orientação NE-SW.

A partir de uma análise geral do recorte estudado, é possível perceber a diferença entre a dissecação do relevo da bacia do rio Iguaçu e a dissecação do relevo da bacia do rio Ribeira. Na primeira há o predomínio de padrões de relevo de menor amplitude altimétrica e menor declividade, como as planícies fluviais, as colinas e as colinas onduladas. Por sua vez, na bacia do rio Ribeira existe um predomínio de padrões de relevo caracterizados por maiores amplitudes altimétricas e maiores declividades, como os morrotes ondulados, morros ondulados, morros fortemente ondulados e morros elevados.

Esta marcante diferença de dissecação está relacionada às estruturas geológicas, que influenciam sobretudo na rede de drenagem, na ação denudacional diferencial sobre as distintas litologias e no nível de base das bacias, sendo a do rio Ribeira exorréica e a do rio Iguaçu endorréica. A bacia do rio Ribeira, como mostra a Figura 1, é marcada pela presença mais numerosa de diques, falhas, dobras e fraturas, quando comparado a bacia do rio Iguaçu. Estas estruturas, por sua vez, são importantes tanto na orientação das direções das formas de relevo, quanto no processo de dissecação.

Este cenário pode ser observado, por exemplo, devido à presença de um enxame de diques de diabásio na porção centro-norte do recorte estudado. Estas estruturas se dispõe de forma paralela e estão orientados na direção NW-SE, tendo sido ativados pelo movimentos orogenéticos positivos ligados ao Arqueamento de Ponta Grossa (FIORI, 1985), durante a separação dos continentes sul-americano e africano (e consequente abertura do oceano Atlântico), quando antigas linhas de fraqueza no embasamento foram reativadas, desenvolvendo uma série de falhas e fraturas sobre rochas de cobertura metassedimentos (FASSBINDER, 1990). Estas falhas e fraturas, em sua maioria, foram posteriormente preenchidas por diabásio durante os eventos de magmatismo basáltico Juro-Cretáceos (MINEROPAR, 2001). Por sua vez, a presença destes diques propiciaram um cenário de erosão diferencial, onde os metassedimentos da Formação Votuverava (pertencente ao Grupo Setuva) vem sendo erodidos com maior intensidade do que as rochas diabásicas, fazendo com as estruturas dos diques se destaquem como as porções mais elevadas do relevo, desenvolvendo vales fortemente dissecados e orientado na direção NW-SE, onde predominam padrões de relevo de morros fortemente ondulados e morros elevados. A presença destes diques também condiciona a dissecação dos vales que caracterizam os padrões de relevo de morrotes ondulados, morros ondulados e morros fortemente ondulados na Formação Capiru (pertencente ao Grupo Açungui) e no Complexo Gnáissico-Migmatítico, inseridos na bacia do rio Ribeira, orientando as cristas destes padrões na direção NW-SE.

Além dos diques de diabásio associados ao Arco de Ponta Grossa, estruturas ligadas ao Sistema Transcorrente da Lancinha também condicionam o relevo da área. Um exemplo é citado por Salamuni (1998), onde na Formação Capiru o relevo de cristas alongadas (que foram classificados neste trabalho como os morrotes ondulados, morros ondulados e morros fortemente ondulados) são orientados na direção NE$\mathrm{SW}$, sendo que os vales intermeados entre as cristas representam falhamentos ligados a zona de cisalhamento Lancinha.

O desenvolvimento de padrões de relevo de maior dissecação na bacia do rio Ribeira também é influenciado por fatores litológicos. Por exemplo, os maciços graníticos, que se formaram pela ascensão de massas graníticas em pequenas zonas transtencionais ao longo de lineamento, e foram alojados em dobras escalonadas antiformais (FASSBINDER, 1990), como o Suíte Monzo-granito (Granito Morro Grande) e o Suíte Sienogranitos, condicionam, por erosão diferencial, a existência de porções de maior amplitude altimétrica, que se configuram como morros elevados, no centro norte da área de estudo. Também, na Formação Capiru (tanto em sua porção inserida na bacia do rio Ribeira quanto na porção inserida na bacia do rio Iguaçu), a presença de quartzitos desenvolveram, por erosão diferencial, picos que se apresentam como hog-backs na direção NE-SW (SALAMUNI et al., 2013), classificados pela técnica aplicada como morros ondulados ou morros fortemente ondulados.

Apesar de apresentar, na maior parte de sua área, padrões de relevo de maior dissecação, a bacia do rio Ribeira é caracterizada também por padrões de relevo de menor dissecação, sobretudo nas porções mais próximas ao divisor de águas com a bacia do rio Iguaçu. Isso se deve, segundo Nascimento et al. (2012) por processos de capturas recentes do sistema hidrográfico da bacia do Alto Ribeira sobre a bacia do Alto Iguaçu, cujo regime erosivo mais acentuado provoca o rejuvenescimento desse relevo. 


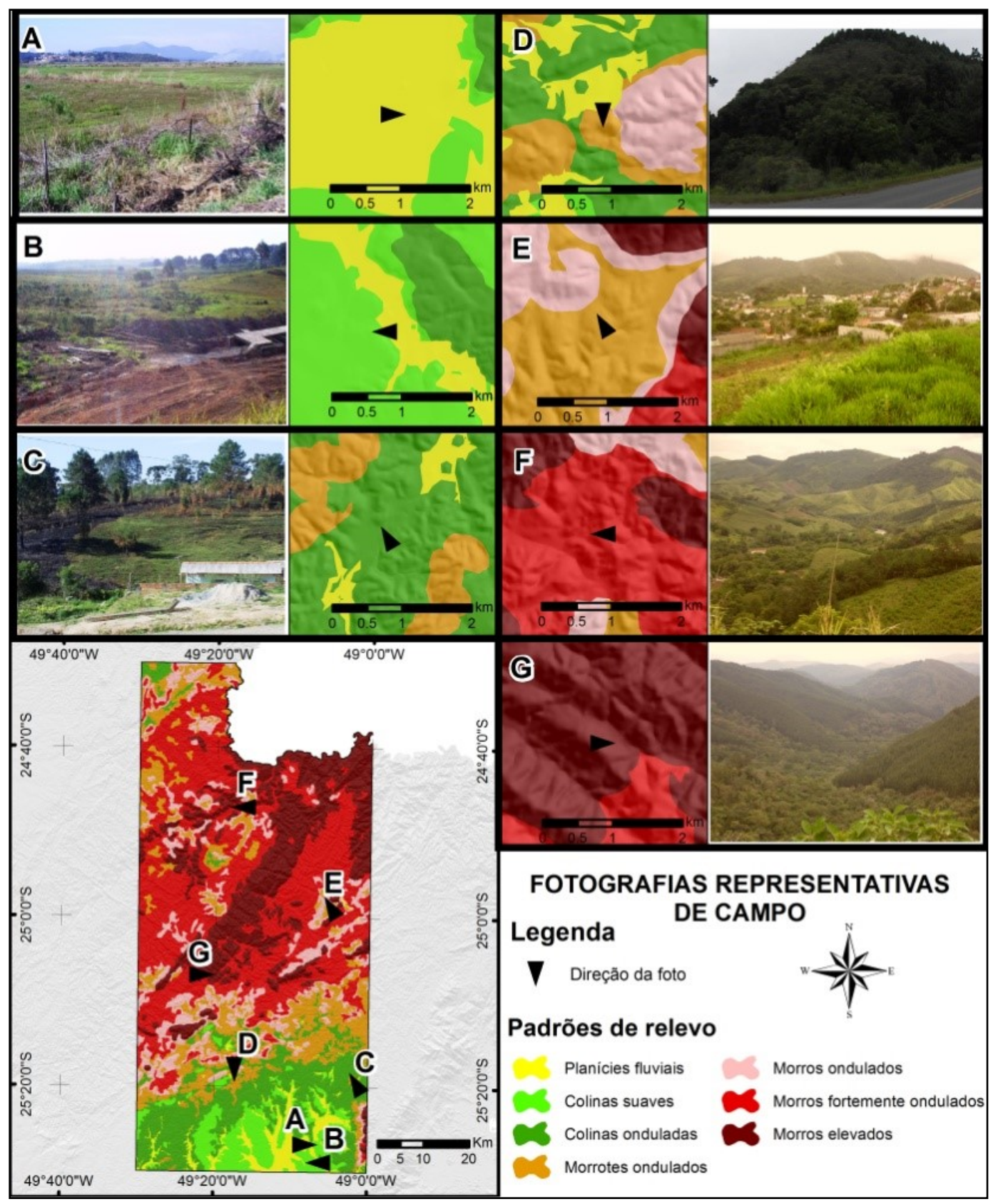

Figura 8: A: Planícies fluviais; B: Colinas suaves; C: Colinas onduladas; D: Morrotes ondulados; E: Morros ondulados; F: Morros fortemente ondulados; G: Morros elevados.

No contato da Formações Capiru com a Formação Perau e o Complexo Metamórfico Indiferenciado (que coincide com a Falha da Lancinha) apresenta uma abrupta mudança de relevo. Na área da Formação Capiru há o predomínio da presença de morrotes ondulados, entretanto na Formação Perau predomina morros elevados e no Complexo Metamórfico Indiferenciado predominam os morros ondulados e os morros fortemente ondulados. Este cenário evidencia o controle litológico sobre o nível de dissecação sobre estas áreas, influenciando na formação dos padrões de relevo.

Por sua vez, diferentemente da bacia do rio Ribeira, o relevo da bacia do rio Iguaçu é caracterizado pela presença de padrões de menor dissecação. Na abrangência do recorte de estudo a área dessa bacia hidrográfica coincide com a Bacia Sedimentar de Curitiba, que é constituída pela Formação Guabirotuba e os sedimentos inconsolidados colúvio-aluvionares recentes (ou do Quartenário), além de embasamento de rochas cristalofilinas (Suíte Álcali-granito) e os metassedimenos do Grupo Açungui (Formação Capiru), e de diques básicos de idade Mesozoica (SALAMUNI, 1998; SALAMUNI et al., 2013).

Sob a região do Alto Iguaçu a litologia apresenta grande influência sobre o desenvolvimento dos padrões de relevo, havendo uma sobreposição entre as áreas de predominância de cada padrão de relevo com os tipos litológicos. O primeiro caso observado foi a área dos sedimentos recentes, onde as planícies fluviais do rio Iguaçu e principais contribuintes se desenvolveram. Salamuni (1998) comenta que o rio Iguaçu e seus formadores estão dissecando a bacia sedimentar e ao mesmo tempo depositando sedimentos no vale de 
inundação principal. Este fato é observado pela pediplanação resultante da erosão lateral nos talvegues posicionados no interior e arredores da bacia de Curitiba. Entretanto, pequenas porções de planícies fluviais também são encontradas em áreas de outros tipos litológicos, como na Formação Capiru.

No segundo caso, a Formação Guabirotuba condiciona o desenvolvimento de colinas, e no terceiro caso, o Complexo Gnáissico-Migmatítico, condiciona o desenvolvimento de colinas onduladas. O predomínio de cada padrão de relevo em determinada litologia é refletido também na sua densidade de drenagem, pois segundo Salamuni et al. (2013), na Formação Guabirotuba a drenagem apresenta menor densidade se comparado ao Complexo Gnáissico-Migmatítico. Assim, as áreas de maior densidade de drenagem apresentam maior média da declividade, que é exatamente o atributo que diferenciou o padrão de relevo colinas do padrão de relevo colinas onduladas.

O último caso se apresenta na área de Suíte Álcali-granito, localizados nos Blocos Soerguidos do Primeiro Planalto. A litologia condicionou o desenvolvimento de padrões de relevo mais dissecados na área, devido a erosão diferencial, onde as rochas sedimentares da Formação Guabirotuba e as rochas do Complexo Gnáissico-Migmatítico erodiram de maneira mais intensa se comparado ao maciço granítico. Os blocos soerguidos apresentam uma faixa de transição entre as áreas mais dissecadas (classificadas como morros elevados) e o entorno (classificados como colinas onduladas), onde são encontrados morrotes ondulados e morros ondulados. Esse relevo transicional é resultado da maior intensidade erosiva nas áreas do maciço próximas aos limites com outras unidades geológicas.

Por sua vez, na Formação Capiru observa-se importante controle estrutural sobre o relevo, entretanto ainda apresentando controle litológico. Neste caso, padrões de relevo de morrotes ondulados e morros ondulados se destacam sobre áreas de colinas onduladas devido a presença de quartzitos, que por erosão diferencial erodiram com menor intensidade do que os mármores dolomiticos e metadolomitos do entorno. Estas áreas classificadas como morrotes ondulados e morros ondulados apresentam orientação na direção NE-SW, devido a influência de estruturas ligadas à Falha da Lancinha.

Assim como no relevo da bacia do rio Iguaçu, na porção extremo-norte, drenada pela bacia do rio Itararé, o relevo apresenta menor dissecação. O padrão de relevo colinas onduladas é condicionado pelo Complexo Granítico Cunhaporã, desenvolvendo um relevo menos dissecado quando comparado ao relevo presente ao sul, na bacia do Ribeira, que é desenvolvido sobre os Suítes Monzogranítos e sobre a Formação Itaiacoca do Grupo Açungui.

Analisando o relevo regional da área de estudo, tem-se que uma importante diferença na configuração do seu relevo está associada aos limites das bacias hidrográficas entre o Iguaçu e Ribeira, reflexo da energia resultante do nível de base regional de cada uma delas. Desse modo, na bacia do rio Iguaçu prevalece a configuração de vales abertos, resultando em padrões de relevo menos dissecados, enquanto que na bacia do rio Ribeira, a forte atuação erosiva controlada por estruturas geológicas e distintos litotipos, resulta em padrões de relevo mais dissecados.

Enfocando então na discussão sobre a aplicação de técnicas geomorfométricas, a proposta apresentada neste trabalho deve ser classificada como uma técnica semiautomatizada, pois seus resultados, apesar de representarem as feições do relevo conforme a realidade de campo, necessitaram de três situações de ajustes pautados em interpretação visual a partir de critérios subjetivos, em virtude das limitações que a técnica automatizada apresenta.

A primeira situação de ajuste está relacionada a necessidade de incorporar pequenas porções de um padrão de relevo, devido a mesma apresentar características visuais muito semelhantes as do padrão de relevo do entorno. Um exemplo foi a incorporação das três porções do padrão de relevo de morrotes fortemente ondulados (Figura 9A) ao padrão de relevo de morros fortemente ondulados.

A segunda situação se refere às áreas que, devido ao fato do raio utilizado no cálculo dos atributos topográficos ser menor que o comprimento de suas vertentes, acabaram por apresentar efeito de borda, ou seja, apresentam uma delgada área mapeada entre dois outros padrões de relevo, sendo esta pertencente a um padrão de relevo com características morfométricas intermediárias quando comparado aos outros dois padrões vizinhos (Figura 9B).

A terceira situação se refere a áreas onde, em razão do raio de vizinhança utilizado no cálculo dos atributos topográficos serem maiores que o comprimento de suas vertentes, o limite entre dois padrões de relevo acabou por ser mapeado no meio da vertente, e não na drenagem (Figura 9C).

Da área total mapeada, apenas $1,82 \%$ teve a classificação do padrão de relevo modificada pelos ajustes, sendo os morros elevados os que mais necessitaram de ajustes (5,8\% de sua área mapeada foi modificada), seguidos pelos morros ondulados $(2,76 \%)$ e morros fortemente ondulados $(0,82 \%)$. 


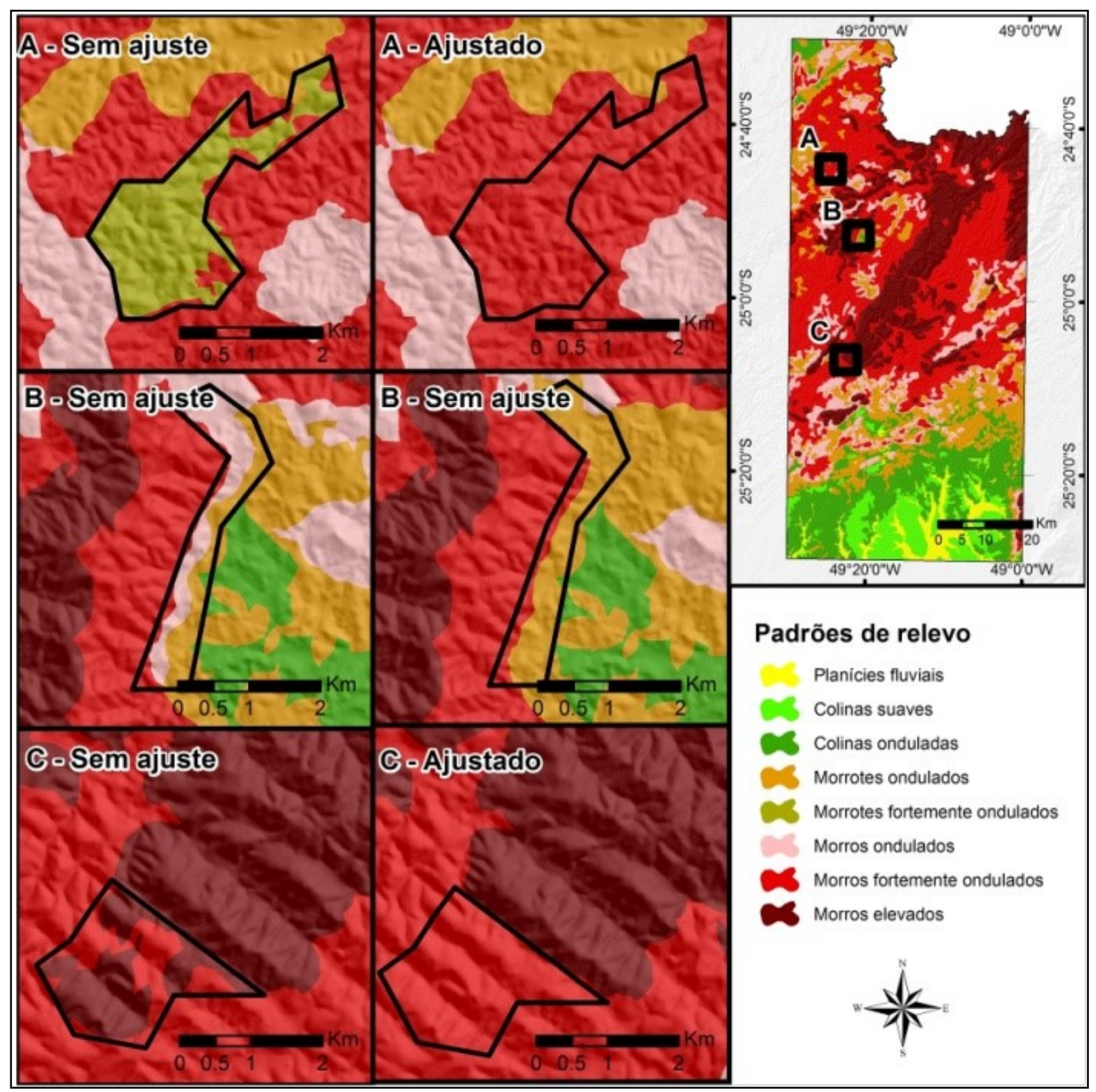

Figura 9: A: Porção de morrotes fortemente ondulados incorporado aos morros fortemente ondulados; B: Porção de morros ondulados incorporado aos morrotes ondulados; C: Porção de morros elevados incorporado aos morros fortemente ondulados. Fonte: Autores.

Comparando o resultado da classificação com os ajustes implementados, com as descrições dos pontos visitados em campo, detectou-se que 18 dos 20 pontos de controle possuem descrição correspondente ao que foi identificado no mapeamento. Deste modo, em apenas dois pontos houve divergência. O primeiro ponto que não possuiu correspondência entre a descrição de campo e a classificação foi descrito como uma área de morros, entretanto foi mapeado como área de morrotes. O segundo ponto foi, o qual, em parte de sua descrição, indica que ao sul há um conjunto de padrão de relevo em morrotes, entretanto mapeou-se parte desse conjunto como morrotes e outra parte como morros ondulados. Esses erros ocorrem devido à subjetividade em classificar, mesmo em campo, muitas feições geomorfológicas, devido a estas apresentarem morfologia com características de diferentes padrões de relevo. Outra possível explicação é a limitação da área de observação em campo, não permitindo que o observador tenha uma visão completa de todo o conjunto do relevo, descrevendo e classificando o ponto visitado conforme as características daquela pequena porção de relevo o qual consegue enxergar. Devido à escala final pretendida para o mapa e conforme a proposta da técnica aplicada neste trabalho, estas pequenas porções foram incorporadas ao padrão de relevo que caracteriza o conjunto todo. 


\section{Considerações Finais}

A técnica empregada apresentou resultados fidedignos à realidade de campo, com a correspondência de 90\% entre os resultados obtidos e as descrições dos pontos de controle de campo visitados, mostrando aplicabilidade na identificação de padrões de relevo. Essa técnica, sendo baseada na geomorfometria, demanda muito menos tempo de trabalho do que as onerosas técnicas tradicionais de mapeamento.

$\mathrm{O}$ uso de critérios quantitativos e análise digital possibilitaram a minimização da subjetividade na detecção dos limites entre as unidades dos padrões de relevo, pois uma vez definidos os critérios eles podem ser aplicados para áreas com as características semelhantes. Porém, a definição dos intervalos de discretização dos atributos topográficos requer o conhecimento de geomorfologia associado a atividades de campo. Além disso, a classificação realizada requer ajustes manuais quando não condizentes com a conferência de campo.

Outro aspecto relevante foi a utilização de distintos raio para a janela de leitura das células do cálculo dos atributos topográficos, no qual foram considerados os valores de moda do comprimento das vertentes nas subunidades morfoesculturais. Desta maneira, possibilitou-se minimizar os erros associados aos efeitos de borda, além de adaptar a classificação quantitativa dos padrões de relevo às características morfológicas predominantes de cada subunidade morfoescultural, evitando sua generalização.

O trabalho também possibilitou a experimentação do método desenvolvido no âmbito do projeto de mapeamento geomorfológico que será empregado em todo o território do Paraná, denotando como uma ferramenta aplicável como subsídio a cartografia geomorfológica, pois permitiu a classificação de aspectos morfológicos. Portanto, demostrou exequibilidade das técnicas geomorfométricas na identificação de padrões de relevo, com coerência dos resultados alcançados e fidedignadade ante a realidade de campo.

\section{Agradecimentos}

Os autores agradecem ao Conselho Nacional de Desenvolvimento Científico e Tecnológico (CNPq) pela disponibilização dos recursos financeiros que possibilitaram a realização do trabalho e os levantamentos de campo, obtidos por meio do projeto Mapeamento Geomorfológico do Estado do Paraná apoiado em análise digital do relevo, Processo $\mathrm{n}^{\mathrm{o}}$ 456244/2014-0, Apoio a Projetos de Pesquisa / MCTI/CNPQ/Universal 14/2014 - Faixa A.

\section{REFERÊNCIAS}

AUGUSTIN, C. H. R.; FONSECA, B. M.; ROCHA, L. C. Mapeamento geomorfológico da Serra do Espinhaço Meridional: primeira aproximação. Geonomos. v. 19. n. 2. p. 50-69, 2011.

BORTOLINI, W.; SILVEIRA, C. T.; SILVEIRA, R. M. P. Emprego de técnicas geomorfométricas na identificação de padrões de relevo. Revista Ra'e Ga - O Espaço Geográfico em Análise. Curitiba, v. 41, Temático de Geomorfologia, p. 131-150, ago. 2017.

CARNEIRO, C. D.; SOUZA, J. J. Mapeamento geomorfológico em escala de semidetalhe da região de Jundiaí Atibaia. Revista Brasileira de Geomorfologia. v. 4, n. 2. p. 17-30, 2003.

CPRM - SERVIÇO GEOLÓGICO DO BRASIL; IPT - INSTITUTO DE PESQUISAS TECNOLÓGICAS. Cartas de suscetibilidade a movimentos gravitacionais de massa e inundações - 1:25.000. Ed. 1 (Nota técnica explicativa). São Paulo, 2014.

DIKAU, R. The application of a digital relief model to landform analysis. In: RAPER, J. F. (Ed.), Three Dimensional Applications in Geographical Information Systems. London: Taylor \& Francis,1989. p. 51-77.

DIKAU, R.; BRABB, E. E.; MARK, R. M. Landform Classification of New Mexico by Computer. Open File report 91-634. U.S. Geological Survey, 1991.

DINIZ, M. T. M.; OLIVEIRA, G. P.; MAIA, R. P.; FERREIRA, B. Mapeamento geomorfológico do estado do Rio Grande do Norte. Revista Brasileira de Geomorfologia. v. 18, n. 4, p. 689-701, dez. 2017.

EL-SHEIMY, N.; VALEO, C.; HABIB, A. Digital Terrain Modelling: acquisition, manipulation, and applications. Norwood, MA: Artech House, Inc., 2005. 257 p. 
EVANS, I. S.; MINÁR, J. A classification of geomorphometric variables. Geomorphometry, Redlands, USA, 105-108, 2011.

FASSBINDER, E. Análise estrutural da Falha da Lancinha: estado do Paraná. 1990. Dissertação (Mestrado em Geologia) - Programa de Pós-Graduação em Geoquímica e Geotectônica, Universidade de São Paulo, São Paulo.

FIORI, A. P. A Falha da Lancinha no pré-Cambriano paranaense: reflexo de uma falha profunda? Boletim Paranaense de Geociências, v. 36. P. 01-14. 1985.

FIORI, A. P. Tectônica e estratigrafia do Grupo Açungui-PR. Boletim IG-USP, Sér.Cient. v. 3. p. 55-74, 1992.

GERASSIMOV, I. P.; MESCHERIKOV, J. L. Morphostructure. In: FAIRBRIDGE, R. W. (Ed.). The encyclopedia of geomorphology. New York: Reinhold Book Corp., 1968.

GOMES, S.M.A; SILVEIRA, R.M.P; SILVEIRA, C.T. Aplicação de técnicas geomorfométricas para classificação de formas do relevo em Campo Largo, estado do Paraná - Brasil. Revista Geografar, 13, 1, 75-97, 2018.

GRIFFITHS, J.; SMITH, M. J..; PARON, P. Introduction to Applied Geomorphological Mapping. SMITH, M. J.; PARON, P.; GRIFFITHS, J. (eds.) Geomorphological Mapping: Methods and Applications. Developments in Earth Surface Processes vol 15, Elsevier, 2011.

GUADAGNIN, P. M. A.; TRENTIN, R. Compartimentação geomorfológica da bacia hidrográfico do Arrioi Caverá - RS. Geo UERJ. Rio de Janeiro, v.16, n. 25, p.183-199, 2014,

HENGL, T. Finding the right pixel size. Computers \& Geosciences. 32, p. 1283-1298, 2006.

HENGL, T; MCMILLAN, R. A. Geomorphometry: A Key to Landscape Map and Modelling. In: HENGL, T.; REUTER, H. I. (eds.) Geomorphometry - Concepts, Software, Applications, Series Developments in Soil Science vol. 33, Amsterdam: Elsevier, pp. 433-460, 2009.

HUTCHINSON, M. F. Calculation of hydrologically sound digital elevation models. Paper presented at Third International Symposium on Spatial Data Handling at Sydney, Australia, 1988.

IWAHASHI, J. ; PIKE, R. J. Automated classification of topography from DEMs by an unsupervised nestedmeans algorithm and a three-part geometric signature. Geomorphology. 86, p. 409-440, 2007.

MESCERJAKOV, J. P. Les concepts de morphostruture et de morphosculture: un nouvel instrument de l'analyse géomorphologique. Annales de Géographie, Paris, t. 77, n. 423, p. 539-552, 1968.

MINÁR, J.; EVANS, I. S. Elementary forms for land surface segmentation: the theoretical basis of terrain analysis and geomorphological mapping. Geomorphology 95 (3-4), p. 236-259, 2008.

MINEROPAR - SERVIÇO GEOLÓGICO DO PARANÁ. Atlas geológico do estado Paraná. Minerais do Paraná, Curitiba, 2001.

NASCIMENTO, E. R.; REIS NETO, M. J.; REBELO, A. M. A.; SAMPAIO, T. V. M.; SILVEIRA, C. T. Parâmetros geomorfométricos do relevo no entendimento do nível de exposição dos sistemas cársticos na região limítrofe das bacias hidrográfi cas do Alto Iguaçu e do Alto Ribeira - Região norte de Curitiba - PR. Revista Brasileira de Geociências. v. 42, n. 1, p. 81-90, 2012.

OKA-FIORI, C., SANTOS, L.J.C., CANALI, N.E., FIORI, A.P., SILVEIRA, C.T., SILVA, J.M.F., ROSS, J.L.S. Atlas geomorfológico do estado do Paraná: Escala base 1:250.000 modelos reduzidos 1:500.000. Curitiba, Minerais do Paraná SA. - MINEROPAR; Universidade Federal do Paraná. Curitiba, 2006. 59p.

PIKE, R. J. Geomorphometry - diversity in quantitative surface analysis. Progress in Physical Geography. v. 24, n. 1, p. 1-20, 2000.

PIKE, R. J.; EVANS, I., HENGL, T. Geomorphometry: A Brief Guide. In: HENGL, T.; REUTER, H. I. (eds.) Geomorphometry - Concepts, Software, Applications, Series Developments in Soil Science vol. 33, Amsterdam: Elsevier, p. 3-30, 2009.

PONÇANO, W. L. (Coord.) et al. Mapa geomorfológico do Estado de São Paulo. São Paulo: IPT, 1981. 2 v. (Publicação IPT, 1 183; Monografias, 5).

RADAM, INSTITUTO BRASILEIRO DE GEOGRAFIA E ESTATÍSTICA - IBGE. Relatório de geomorfologia - Folha SG.22 Curitiba, Folha SG.21 Asunción e Folha SG.23 Iguape. Volume. 351983.

ROSA FILHO, E. F.; GUARDA, M. J. Compartimentação hidrogeológica da Formação Capiru na região norte de Curitiba-PR, Brasil. Águas Subterrâneas., v. 22, n. 01, p. 67-74, 2008. 
ROBAINA, L.E.S; TRENTIN, R.; LAURENT, F. Compartimentação do estado do Rio Grande do Sul, Brasil, através do uso de geomorphons obtidos em classificação topográfica automatizada. Revista Brasileira de Geomorfologia, São Paulo, v.17, n.2, p.287-298, 2016.

ROBAINA, L.E.S; TRENTIN, R.; CRISTO, S. S. V.; SCCOTI, A. A. V. Application of the geomorphons to the landform classification in Tocantins state, Brazil. Revista Ra'e Ga, v. 41 Temático de Geomorfologia, 37-48, 2017.

ROSS, J. S.; MOROZ, I.C. Mapa geomorfológico do estado de São Paulo. São Paulo: Laboratório de Geomorfologia Depto de Geografia FFLCHUSP/Laboratório de Cartografia Geotécnica - Geologia Aplicada IPT/FAPESP, 1997.

ROSS, J. S. Registro cartográfico dos fatos geomorfológicos e a questão da taxonomia do relevo. Rev. Geografia. São Paulo, v. 6, p. 17-29, 1992.

SALAMUni, E. Tectônica da Bacia Sedimentar de Curitiba. 1998. Tese (Doutorado em Geologia) - Instituto de Geociências e Ciências Exatas, Universidade Estadual Paulista, Rio Claro.

SALAMUNI, E.; STELlFELD, M. C. Banco de dados geológico geo-referenciado da Bacia Sedimentar de Curitiba (PR) como base de Sistema de Informação Geográfica (SIG). Boletim Paranaense de Geociências, n. 49, p. 21-31, 2001.

SALAMUNI, E.; NASCIMENTO, E. R.; SILVA, P. H. K.; OKA-FIORI, C. Geomorfologia do município de Curitiba-PR. Revista Brasileira de Geomorfologia. v. 14, n. 4, p. 327-341, 2013.

SAMPAIO, T.V.M. AUGUSTIN, C.H.R.R. Índice de Concentração da Rugosidade: uma nova proposta metodológica para o mapeamento e quantificação da dissecação do relevo como subsídio a cartografia geomorfológica. Revista Brasileira de Geomorfologia. v. 15, n. 1, p. 47-60, 2014.

SANTOS, L. J. C. et al. Mapeamento Geomorfológico do Estado do Paraná. Revista Brasileira de Geomorfologia. v. 7, n. 2. p. 03-11. 2006

STEINKE, V. A.; SANO, E. E. Semi-automatic identification, GIS-based morphometry of geomorphic features of Federal District of Brazil. Revista Brasileira de Geomorfologia. v. 12, n. 1, p. 3-9, 2011.

SILVA, J. M. F; SANTOS, L. J. C.O sensoriamento remoto na pesquisa geomorfológica: aplicações no município de Antonina - PR. Revista Geonorte, Edição Especial, v.2, n.4, p.1636-1645, 2012.

SILVEIRA, C. T; SILVEIRA, R. M. P. Índice de Posição Topográfica (IPT) para classificação geomorfométrica das formas de relevo no estado do Paraná - Brasil. Revista Ra'e Ga, v. 41, p. 98-130, 2017.

SILVEIRA, C. T.; SILVEIRA, R. M. P.; TRENTIN, R.; ROBAINA, L. E. S. Classifi cação Automatizada de Elementos de Relevo no Estado do Paraná (Brasil). Revista Brasileira de Geomorfologia, v.19, n.1, p.33-57, 2018

SILVEIRA, R. M. P.; SILVEIRA, C. T.; OKA-FIORI, C. Análise digital do relevo aplicada no mapeamento de unidades geomorfológicas. Revista Geografar, Curitiba, v. 7, n. 2, p. 43-68, 2012.

SILVEIRA, R. M. P.; SILVEIRA, C. T.; OKA-FIORI, C. Emprego de técnicas de inferência espacial para identificação de unidades de relevo apoiado em atributos topográficos e árvore de decisão. Revista Brasileira de Geomorfologia, v.15, n.1, p.87-101, 2014.

SILVEIRA, R. M. P.; SILVEIRA, C. T. Classificação hierárquica automatizada de formas do relevo no estado do Paraná apoiada na modelagem digital do terreno. Revista Brasileira de Geografia Física, v. 8 n. 5, p. 1509$1523,2015$.

SILVEIRA, R. M. P.; SILVEIRA, C. T. Análise digital do relevo aplicada à cartografia geomorfológica da porção central da Serra do Mar Paranaense. Revista Brasileira de Geomorfologia, São Paulo, v. 17, n. 4, 615-629, 2016.

SOUZA, L. F.; SAMPAIO, T. V. M. Aplicação do Índice de Concentração da Rugosidade à identificação de classes de dissecação do relevo: uma proposta de quantificação e automatização em ambiente SIG. In: Simpósio Brasileiro de Ciências Geodésicas e Tecnologias da Geoinformação, 3., 2010, Recife -PE. Anais eletrônicos... Recife, 2010. Disponível em: < http://lsie.unb.br/ugb/sinageo/8/10/17.pdf>

TRENTIN, R.; ROBAINA, L. E. S.; SILVEIRA, C. T. Compartimentação geomorfométrica da bacia hidrográfico do rio Itú/RS. Revista Brasileira de Geomorfologia. v. 16, no 2, p. 219-237, 2015.

TINÓS, T.M.; FERREIRA, V.V.; RIEDEL, P.S.; ZAINE, J.E. Aplicação e avaliação de metodologia de classificação automática de padrões de formas semelhantes do relevo. Revista Brasileira de Geomorfologia, São Paulo, v.15, n.3, p.353-370, 2014. 
TOBLER, W. R. The development of analytical cartography - a personal note. Cartography and Geographic Information Science. v. 27, n.3, 189-194, 2000.

VASCONCELOS. V.; CARVALHO JÚNIOR, O. A.; MARTINS, E. S. COUTO JUNIOR, A. F.; GUIMARÃES, R. F.; GOMES, R. A. T. Sistema de classificação geomorfométrica baseado em uma arquitetura sequencial em duas etapas: árvore de decisão e classificador espectral, no Parque Nacional Serra da Canastra. Revista Brasileira de Geomorfologia, v. 13, n. 2, p. 171-186, 2012.

VERSTAPPEN, H. T. Old and New Trends in Geomorphological and Landform Mapping. SMITH, M. J.; PARON, P.; GRIFFITHS, J. (eds.) Geomorphological Mapping: Methods and Applications. Developments in Earth Surface Processes vol 15, Elsevier, 2011.

WEISS, A. Topographic Position and Landforms Analysis. Poster presentation, ESRI User Conference, San Diego, CA, 2001.

WILSON, J. P.; GALLANT, J. C. (eds.). Terrain analysis: principles and applications. New York: John Wiley \& Sons, p.1-27, 2000.

WILSON, J. P. Digital terrain modelling. Geomorphology. v. 137. p. 107-121. 2012.

WOOD, J. The geomorphological characterisation of digital elevation models. Leicester, UK, 1996. 185p. PhD Thesis - University of Leicester. Disponível em: http://www.soi.city.ac.uk/ jwo/phd.

ZHOU, Q.; LEES, B.; TANG, G. (eds.). Advances in Digital Terrain Analysis. Series: Lecture Notes in Geoinformation and Cartography. Berlim: Springer-Verlag, 2008. 